\title{
Effect of Minor Cr Additions on Dispersed Phase and Properties of Al-Zn-Mg-Cu-Zr Alloys
}

\author{
Xingzhi Liao ${ }^{1,2}$, Yanxi Li ${ }^{1,2}$, Pengxuan Dong1,2, Kanghua Chen1,2,3* \\ ${ }^{1}$ Science and Technology on High Strength Structural Materials Laboratory, Central South University, Changsha, China \\ ${ }^{2}$ Collaborative Innovation Center of Advance Nonferrous Structural Materials and Manufacturing, Central South University, \\ Changsha, China \\ ${ }^{3}$ Light Alloy Research Institute, Central South University, Changsha, China \\ Email: *357793589@qq.com
}

How to cite this paper: Liao, X.Z., Li, Y.X., Dong, P.X. and Chen, K.H. (2020) Effect of Minor Cr Additions on Dispersed Phase and Properties of $\mathrm{Al}-\mathrm{Zn}-\mathrm{Mg}-\mathrm{Cu}-\mathrm{Zr}$ Alloys. Journal of Materials Science and Chemical Engineering, 8, 27-36.

https://doi.org/10.4236/msce.2020.82004

Received: November 18, 2019

Accepted: January 19, 2020

Published: January 22, 2020

Copyright (c) 2020 by author(s) and Scientific Research Publishing Inc. This work is licensed under the Creative Commons Attribution International License (CC BY 4.0).

http://creativecommons.org/licenses/by/4.0/

\section{Open Access}

\begin{abstract}
The influences of $\mathrm{Cr}$ on dispersed phase and properties of $\mathrm{Al}-\mathrm{Zn}-\mathrm{Mg}-\mathrm{Cu}-\mathrm{Zr}$ alloys were investigated by mechanical testing, slow strain rate stress corrosion, intergranular corrosion, combined with optical microscope, scanning electronic microscope, transmission electronic microscopy (OM, SEM, TEM). Research shows that: with the increase of element $\mathrm{Cr}$, the recrystallization and grain growth had been inhibited, the strength, toughness and corrosion resistance of the alloy increased first and then decreased; when added $0.1 \mathrm{wt} \% \mathrm{Cr}$ element, the properties of the alloy are the best. The main reasons of that were as below: when added $0.1 \mathrm{wt} \% \mathrm{Cr}$ element, $(\mathrm{Al}, \mathrm{Cr})_{3}(\mathrm{Zr}, \mathrm{Yb})$ appeared, that cohered with the matrix. When added 0.18 wt\% $\mathrm{Cr}$ element, $(\mathrm{Al}, \mathrm{Cr})_{3}(\mathrm{Zr}, \mathrm{Yb})$ and $\mathrm{Al}_{18} \mathrm{Mg}_{3} \mathrm{Cr}_{2}$ had been found, making adverse effects on alloys. This work studied the effect of $\mathrm{Cr}$ content on recrystallization and grain growth in order to get a new super high strength aluminum alloy.
\end{abstract}

\section{Keywords}

Al-Zn-Mg-Cu-Zr Alloys, Chromium, Dispersed Phase, Property

\section{Introduction}

$\mathrm{Al}-\mathrm{Zn}-\mathrm{Mg}-\mathrm{Cu}$ super high strength aluminum alloys have high specific strength, specific stiffness and good processability, which are widely used in aerospace and civil industry [1] [2] [3]. It is an important way to improve the strength of the alloy to control the size and quantity of the precipitated strengthening phase [4] [5]. With the development of modern Aeronautics and Astronautics, the requirements of new generation aluminum alloy for reducing weight and increas- 
ing life are further improved. It is required to maintain the alloy strength and improve its corrosion resistance and toughness. Therefore, its corrosion resistance becomes an important research direction at present [6] [7]. At present, many scholars use the method of adding trace elements to form multicomponent coherent dispersion phase in aluminum alloy to inhibit recrystallization and improve the toughness and corrosion resistance of ultra-high strength aluminum alloy. Adding $\mathrm{Cr}$ to $\mathrm{Al}-\mathrm{Zn}-\mathrm{Mg}-\mathrm{Cu}-\mathrm{Zr}$ alloys can produce $\mathrm{Al}_{18} \mathrm{Mg}_{3} \mathrm{Cr}_{2}$ dispersion phase, which has no obvious coherent relationship with the matrix. Although it can inhibit recrystallization, the effect is limited and the quenching sensitivity of the alloy is improved, so it should be restrained as much as possible [8]; The addition of $\mathrm{Zr}$ to $\mathrm{Al}-\mathrm{Zn}-\mathrm{Mg}-\mathrm{Cu}-\mathrm{Zr}$ alloys alone will form $\mathrm{Al}_{3} \mathrm{Zr}$ dispersion phase which is coherent with the matrix, and the effect of inhibiting recrystallization is better than that of adding $\mathrm{Cr}$ alone [9] [10]. However, the $\mathrm{L}_{12}$ type $\mathrm{Al}_{3} \mathrm{Zr}$ dispersion phase is unstable, and it is easy to transform into $\mathrm{DO}_{23}$ type $\mathrm{Al}_{3} \mathrm{Zr}$ dispersion phase under high temperature, which is not coherent with the matrix, thus reducing its effect of inhibiting recrystallization [11]. Adding Sc or adding $\mathrm{Sc}$ and $\mathrm{Zr}$ in combination can form $\mathrm{L}_{12}$ dispersion phase $\mathrm{Al}_{3} \mathrm{Sc}$ and $\mathrm{Al}_{3}(\mathrm{Sc}$, $\mathrm{Zr}$ ) which are coherent with the matrix, which can significantly inhibit recrystallization, but Sc is expensive, so large-scale application is almost impossible [12] [13] [14] [15]. The preliminary work of the research group shows that the addition of $\mathrm{Zr}, \mathrm{Cr}$ and $\mathrm{Yb}$ can inhibit recrystallization and improve the strength, toughness and corrosion resistance of the alloy. However, the effect of $\mathrm{Cr}$ content on the microstructure and properties of $\mathrm{Al}-\mathrm{Zn}-\mathrm{Mg}-\mathrm{Cu}-\mathrm{Zr}-\mathrm{Yb}$ alloys is rarely studied. Therefore, the effect of $\mathrm{Cr}$ on the structure and properties of $\mathrm{Al}-\mathrm{Zn}-\mathrm{Mg}-\mathrm{Cu}-\mathrm{Zr}-\mathrm{Yb}$ was further studied by adjusting $\mathrm{Cr}$ content, which laid a foundation for the development of new super aluminum alloy.

\section{Experimental}

In the experiment, high-purity aluminum, industrial pure magnesium and industrial pure zinc (the purity of $\mathrm{Al}, \mathrm{Zn}$ and $\mathrm{Mg}$ is $99.9 \%$ ) are used as raw materials. $\mathrm{Cu}, \mathrm{Zr}, \mathrm{Cr}$ and $\mathrm{Yb}$ are all added in the form of intermediate alloy. See Table 1 for the nominal composition of experimental aluminum alloys while Table 2 is the actual composition of experimental aluminum alloys. Alloy ingots are melted at $700^{\circ} \mathrm{C}-740^{\circ} \mathrm{C}$. Adding $0.2-0.4 \mathrm{wt} \% \mathrm{C}_{2} \mathrm{Cl}_{6}$ into the melting metal alloy to achieve the purpose of degassing and slag removal. Homogenization was carried out in a $45 \mathrm{~mm}$ diameter cylindrical mold preheated to $270^{\circ} \mathrm{C}$ : ingot was homogenized and annealed at $460^{\circ} \mathrm{C}$ for 24 hours. Before hot extrusion, the preheating temperature is $410^{\circ} \mathrm{C}-430^{\circ} \mathrm{C}$, and the extrusion deformation is carried out on a

Table 1. Nominal composition of experimental aluminum alloys (mass fraction, \%).

\begin{tabular}{cccccccc}
\hline Alloys & $\mathrm{Zn}$ & $\mathrm{Mg}$ & $\mathrm{Cu}$ & $\mathrm{Zr}$ & $\mathrm{Yb}$ & $\mathrm{Cr}$ & $\mathrm{Al}$ \\
\hline Al-8.54Zn-2.41Mg-1.3Cu-0.16Zr-0.3Yb & 8.54 & 2.41 & 1.30 & 0.16 & 0.30 & 0 & $\mathrm{Bal}$ \\
$\mathrm{Al}-8.54 \mathrm{Zn}-2.41 \mathrm{Mg}-1.3 \mathrm{Cu}-0.16 \mathrm{Zr}-0.3 \mathrm{Yb}-0.1 \mathrm{Cr}$ & 8.54 & 2.41 & 1.30 & 0.16 & 0.30 & 0.10 & $\mathrm{Bal}$ \\
$\mathrm{Al}-8.54 \mathrm{Zn}-2.41 \mathrm{Mg}-1.3 \mathrm{Cu}-0.16 \mathrm{Zr}-0.3 \mathrm{Yb}-0.18 \mathrm{Cr}$ & 8.54 & 2.41 & 1.30 & 0.16 & 0.30 & 0.18 & $\mathrm{Bal}$ \\
\hline
\end{tabular}


Table 2. Actual composition of experimental aluminum alloys by ICP conversion (mass fraction, \%).

\begin{tabular}{cccccccccc}
\hline Alloys & $\mathrm{Zn}$ & $\mathrm{Mg}$ & $\mathrm{Cu}$ & $\mathrm{Zr}$ & $\mathrm{Yb}$ & $\mathrm{Cr}$ & $\mathrm{Fe}$ & $\mathrm{Si}$ & $\mathrm{Al}$ \\
\hline Al-8.54Zn-2.41Mg-1.3Cu-0.16Zr-0.3Yb-0.1Cr & 8.96 & 2.16 & 1.34 & 0.183 & 0.24 & 0.12 & 0.03 & 0.12 & $\mathrm{Bal}$
\end{tabular}

$500 \mathrm{t}$ press, and the extrusion ratio is 9 . The extruded sample was kept in a $480^{\circ} \mathrm{C}$ resistance furnace for 1 hour, and the aging treatment was carried out at $120^{\circ} \mathrm{C}$ after water quenching for 24 hours.

After solution aging, the alloy sample was polished and etched with Graff Sargent reagent $\left(3 \mathrm{~g} \mathrm{CrO}_{3}+0.5 \mathrm{ml} \mathrm{HF}+84 \mathrm{ml} \mathrm{H}_{2} \mathrm{O}_{2}+15.5 \mathrm{ml} \mathrm{HNO}_{3}\right)$. The recrystallization was observed at low magnification by optical microscope. The microstructures (second phase morphology, size, distribution, etc.) of the alloys were observed by TECNAI G2 20 and JEOL-2100F high resolution transmission electron microscopy. TEM samples were prepared by double jet electrolysis. After the sample thickness is reduced to $100-150 \mu \mathrm{m}$ by grinding the sample, the sample is cut into a $\Phi 3 \mathrm{~mm}$ disc, and the double jet electrolytic thinning is carried out on the Struers TenuPol-2 thinning instrument. The mixed solution of $30 \%$ nitric acid and $70 \%$ methanol solution (volume fraction) is used as electrolyte, the voltage is $20 \mathrm{~V}$, the current is $80-100 \mathrm{~mA}$, and the temperature is controlled at $-30^{\circ} \mathrm{C}$.

Intergranular corrosion test was carried out according to GB7998-87 standard. $57 \mathrm{~g} / \mathrm{L} \mathrm{NaCl}$ and $10 \mathrm{ml} \mathrm{H}_{2} \mathrm{O}_{2}$ (30\%, chemically pure) were used. The intergranular corrosion solution was prepared at the ratio of $50 \mathrm{~cm}^{2} / \mathrm{L}$ (the ratio of corrosion surface area to corrosion medium volume). The test temperature was $35^{\circ} \mathrm{C} \pm 1^{\circ} \mathrm{C}$, and then placed in the air for 6 hours. Wash the corroded sample with distilled water and dry it. Grind the sample on the grinding machine for about $5 \mathrm{~mm}$ (select the cross section perpendicular to the extrusion deformation direction) to make the metallographic sample. The intergranular corrosion of polished samples was observed under metallographic microscope.

Stress corrosion test shall be conducted according to GB/T 15970.7-2000. The samples were taken in the direction of L-T on the Xi'an Rio Tinto slow strain rate corrosion tensile machine. Slow tensile test (SSRT) test working gauge is 25 $\mathrm{mm}$ and plate sample is $2 \mathrm{~mm}$ thick. After the sample is installed, a certain load is applied to reduce the gap as much as possible. The strain rate is $6.67 \times 10^{-6} \mathrm{~s}^{-1}$, and the corrosion solution is $57 \mathrm{~g} / \mathrm{L} \mathrm{NaCl}+10 \mathrm{ml} / \mathrm{L} \mathrm{H}_{2} \mathrm{O}_{2}$.

\section{Results and Discussions}

\subsection{Metallographic Analysis}

Figure 1 shows the microstructure of $\mathrm{Al}-\mathrm{Zn}-\mathrm{Mg}-\mathrm{Cu}-\mathrm{Zr}-\mathrm{Yb}$ alloys with adding different $\mathrm{Cr}$ content. It can be seen from Figure 1(a) that when $\mathrm{Cr}$ is not added, the recrystallization area of the alloy is large and the recrystallization degree of the alloy is serious (the white area is the recrystallization area); when $\mathrm{Cr}$ content reaches $0.1 \mathrm{wt} \%$, as shown in Figure $1(\mathrm{~b})$, there are a large number of submicron 

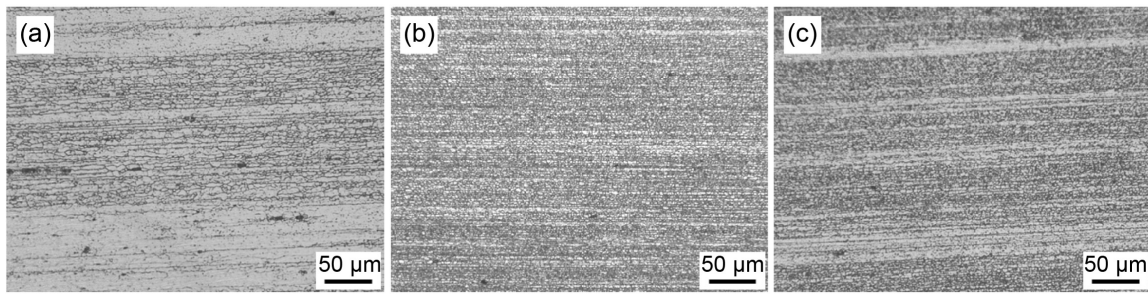

Figure 1. Optical microstructures of $\mathrm{Al}-\mathrm{Zn}-\mathrm{Mg}-\mathrm{Cu}-\mathrm{Zr}-\mathrm{Yb}$ alloys with different $\mathrm{Cr}$ addition. (a) Al-8.54Zn-2.41Mg-1.3Cu-0.16Zr-0.3Yb;

(b) $\mathrm{Al}-8.54 \mathrm{Zn}-2.41 \mathrm{Mg}-1.3 \mathrm{Cu}-0.16 \mathrm{Zr}-0.3 \mathrm{Yb}-0.1 \mathrm{Cr}$;

(c) Al-8.54Zn-2.41Mg-1.3Cu-0.16Zr-0.3Yb-0.18Cr.

fine sub grains in the alloy, and the black sub grain boundary in the figure is obvious, and these sub grains are still in the form of variable fibrous structure distribution; when $\mathrm{Cr}$ content increases to 0.18 . As shown in Figure 1(c), there is no obvious difference in the fibrous sub crystal structure of the alloy compared with the previous $\mathrm{Cr}=1.0 \mathrm{wt} \%$. The results show that the addition of trace $\mathrm{Cr}$ improves the recrystallization resistance of the alloy with intact deformation recovery substructure. When the $\mathrm{Cr}$ content reaches a certain value, the $\mathrm{Cr}$ content $(0.18 \mathrm{wt} \%)$ will continue to increase, and the recrystallization resistance of the alloy will not be significantly improved.

\subsection{TEM Microstructure Analysis of Alloy}

Figure 2 shows the morphology, size and distribution of dispersion phase in $\mathrm{Al}-\mathrm{Zn}-\mathrm{Mg}-\mathrm{Cu}-\mathrm{Zr}-\mathrm{Yb}$ alloy with adding different $\mathrm{Cr}$ amount; Figure 3 shows the selected area diffraction pattern of $\mathrm{Al}-\mathrm{Zn}-\mathrm{Mg}-1.3 \mathrm{Cu}-0.16 \mathrm{Zr}-0.3 \mathrm{Yb}-0.18 \mathrm{Cr}$. It can be seen from the figure that in the case of no $\mathrm{Cr}$ addition, a fine dispersed $\mathrm{Al}_{3}(\mathrm{Zr}$, $\mathrm{Yb}$ ) phase is formed in the alloy. Compared with the case of no $\mathrm{Cr}$ addition and $0.1 \mathrm{wt} \% \mathrm{Cr}$ addition, the number of the second phase with fine dispersion distribution in the alloy is significantly increased. The second phase is $(\mathrm{Al}, \mathrm{Cr})_{3}(\mathrm{Zr}$, $\mathrm{Yb})$ particle by energy spectrum analysis [16]-[23]. When the $\mathrm{Cr}$ content increases to $0.18 \mathrm{wt} \%$, there are two kinds of dispersed phases, one is spherical ( $\mathrm{Al}$, $\mathrm{Cr})_{3}(\mathrm{Zr}, \mathrm{Yb})$ phase, the other is coarse rod-shaped $\mathrm{Al}_{18} \mathrm{Mg}_{3} \mathrm{Cr}_{2}$ phase.

\subsection{Analysis of Mechanical Properties of Alloy}

Table 3 shows the mechanical properties and fracture toughness of $\mathrm{Al}-\mathrm{Zn}-\mathrm{Mg}-\mathrm{Cu}-\mathrm{Zr}-\mathrm{Yb}$ alloy with different $\mathrm{Cr}$ content after peak aging. When the $\mathrm{Cr}$ content increases from $0 \mathrm{wt} \%$ to $0.1 \mathrm{wt} \%$, the strength and fracture toughness of the alloy increase, and when the $\mathrm{Cr}$ content increases further, the strength and toughness decrease. When $\mathrm{Cr}$ content is $0.1 \mathrm{wt} \%$, the strength of the alloy reaches the peak value, and the corresponding strength and toughness are $731.5 \mathrm{Mpa}$, $710.9 \mathrm{Mpa}$ and $37.2 \mathrm{Mpa} \cdot \mathrm{m}^{1 / 2}$ respectively.

Figure 4 shows the tensile fracture morphology of alloys with different $\mathrm{Cr}$ content. When $\mathrm{Cr}$ is not added, the tensile fracture of the alloy is mainly coarse dimple transgranular fracture; when $0.1 \mathrm{wt} \% \mathrm{Cr}$ is added, the tensile fracture of 

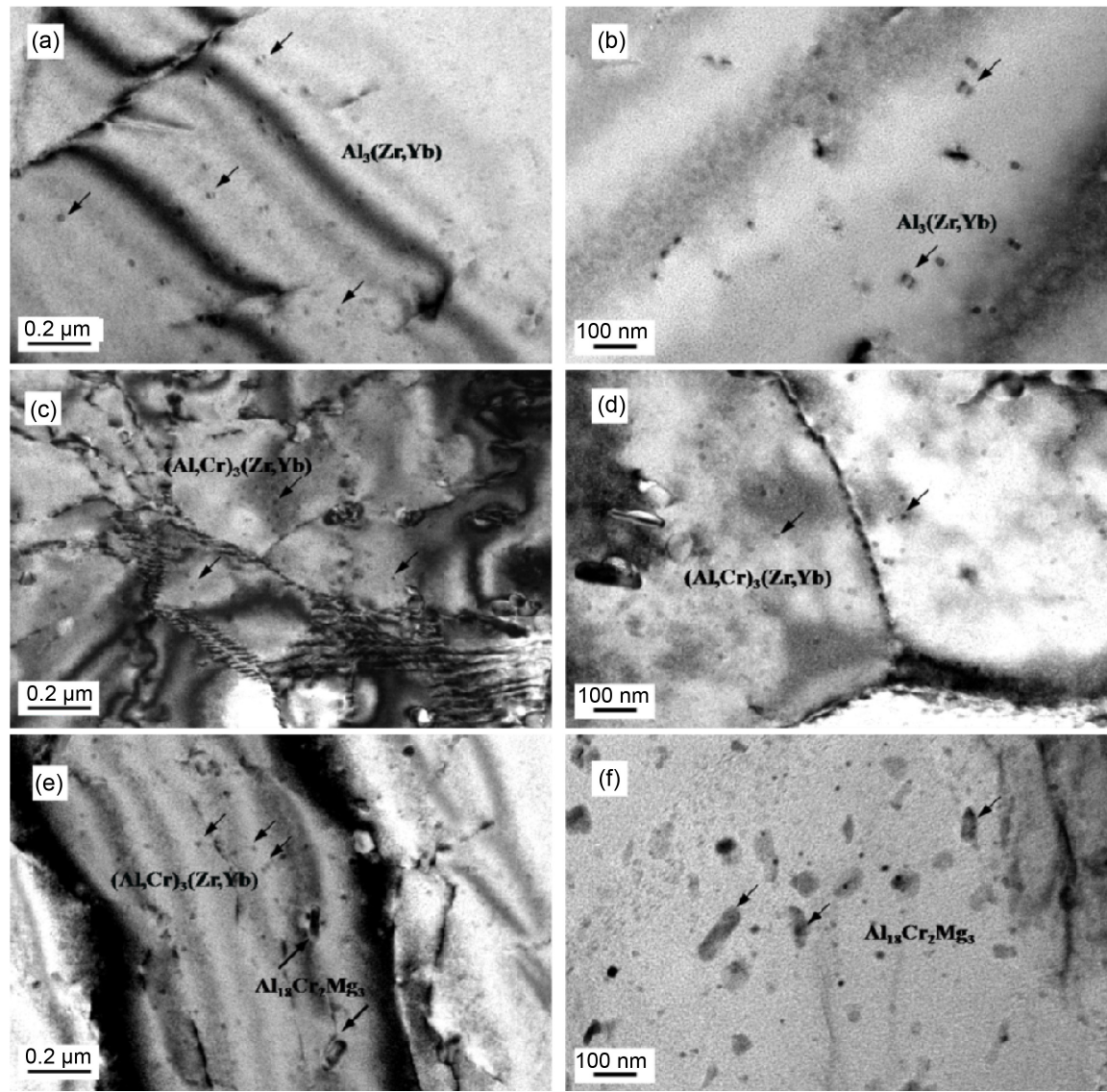

Figure 2. The effect of $\mathrm{Cr}$ to the dispersed phase of the $\mathrm{Al}-\mathrm{Zn}-\mathrm{Mg}-\mathrm{Cu}$ alloys.

(a) (b) Al-8.54Zn-2.41 Mg-1.3Cu-0.16Zr-0.3Yb;

(c) (d) Al-8.54Zn-2.41Mg-1.3Cu-0.16Zr-0.3Yb-0.1Cr;

(e) (f) Al-8.54Zn-2.41 Mg-1.3Cu-0.16Zr-0.3Yb-0.18Cr.
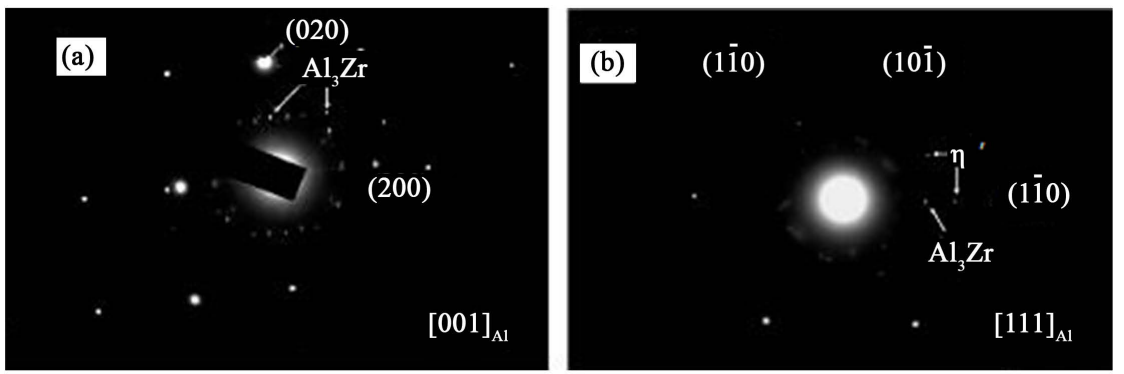

Figure 3. The selected area diffraction of Al-8.54Zn-2.41Mg-1.3Cu-0.16Zr-0.3Yb-0.18Cr.

the alloy is evenly distributed with fine dimples with obvious ductile fracture characteristics; when the $\mathrm{Cr}$ content is increased to $0.18 \mathrm{wt} \%$, the alloy is mainly composed of uniformly distributed fine fracture dimples.

\subsection{Analysis of Intergranular Corrosion Properties}

Figure 5 shows the corrosion depth of cross section (T-S) of Al-Zn-Mg-Cu-Zr-Yb alloy with different $\mathrm{Cr}$ content after intergranular corrosion along its L-T surface. It can be seen from the intergranular corrosion depth that the corrosion 
Table 3. Tensile strength, yield strength and mechanical properties of experimental alloys of different Cr element.

\begin{tabular}{ccccc}
\hline Alloys & $\sigma_{\mathrm{b}} / \mathrm{MPa}$ & $\sigma_{0.2} / \mathrm{MPa}$ & $\delta / \%$ & $\mathrm{~K}_{I C} / \mathrm{MPa}^{\mathrm{m}} \mathrm{m}^{1 / 2}$ \\
\hline Al-8.54Zn-2.41Mg-1.3Cu-0.16Zr-0.3Yb & 683.80 & 660.50 & 9.60 & 34.30 \\
Al-8.54Zn-2.41Mg-1.3Cu-0.16Zr-0.3Yb-0.1Cr & 731.50 & 710.90 & 8.50 & 37.20 \\
Al-8.54Zn-2.41Mg-1.3Cu-0.16Zr-0.3Yb-0.18Cr & 706.80 & 685.00 & 8.70 & 35.60 \\
\hline
\end{tabular}
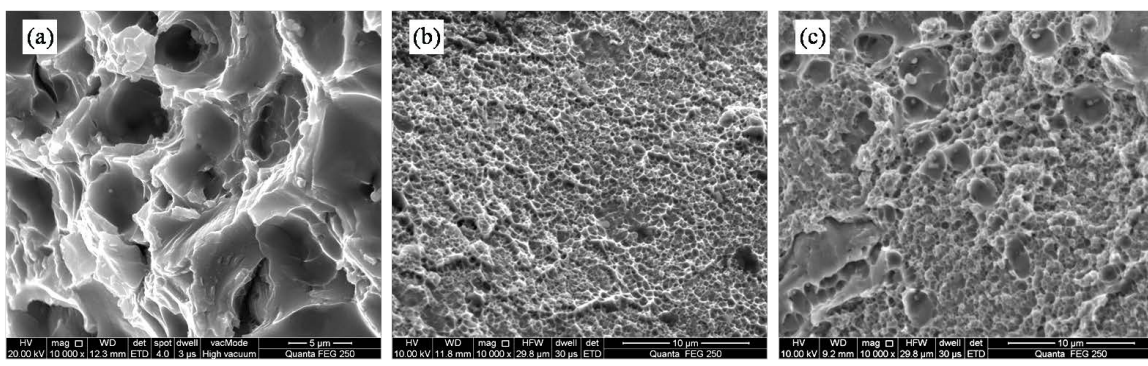

Figure 4. The effect of $\mathrm{Cr}$ element to the tensile fracture morphology of the alloys.

(a) $\mathrm{Al}-8.54 \mathrm{Zn}-2.41 \mathrm{Mg}-1.3 \mathrm{Cu}-0.16 \mathrm{Zr}-0.3 \mathrm{Yb}$;

(b) Al-8.54Zn-2.41Mg-1.3Cu-0.16Zr-0.3Yb-0.1Cr;

(c) $\mathrm{Al}-8.54 \mathrm{Zn}-2.41 \mathrm{Mg}-1.3 \mathrm{Cu}-0.16 \mathrm{Zr}-0.3 \mathrm{Yb}-0.18 \mathrm{Cr}$.
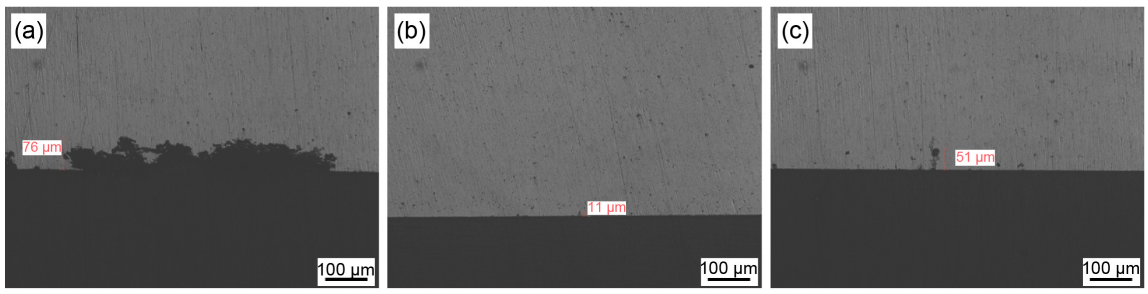

Figure 5. The corrosion cross section of the alloys was determined by different $\mathrm{Cr}$ content. (a) Al-8.54Zn-2.41Mg-1.3Cu-0.16Zr-0.3Yb;

(b) Al-8.54Zn-2.41Mg-1.3Cu-0.16Zr-0.3Yb-0.1Cr;

(c) Al-8.54Zn-2.41Mg-1.3Cu-0.16Zr-0.3Yb-0.18Cr.

depth of the alloy with $\mathrm{Cr}$ content of $0 \mathrm{wt} \%, 0.1 \mathrm{wt} \%, 0.18 \mathrm{wt} \%$ is $76 \mu \mathrm{m}, 11 \mu \mathrm{m}$ and $51 \mu \mathrm{m}$ respectively.

\subsection{Analysis of Stress Corrosion Resistance}

Figure 6 shows the slow drawing curve of alloy with different $\mathrm{Cr}$ content. It can be seen from the figure that with the increase of $\mathrm{Cr}$ content, the stress corrosion cracking time and yield strength of the alloy increase first and then decrease. The results show that the stress corrosion resistance of the alloy is the best when $\mathrm{Cr}$ content is $0.1 \mathrm{wt} \%$.

With the increase of $\mathrm{Cr}(0-0.1 \mathrm{wt})$, the recrystallization resistance of the alloy is improved, and the deformation recovery substructure of the alloy with low $\mathrm{Cr}$ content is retained completely. With the increase of $\mathrm{Cr}$ content $(0.1-0.18 \mathrm{wt})$, the recrystallization resistance of the alloy did not change significantly. The main reason is that when $\mathrm{Cr}$ is not added, the size of precipitated particles is 30 $50 \mathrm{~nm}$. These particles are $\mathrm{Al}_{3}(\mathrm{Zr}, \mathrm{Yb})$ phase (Figure 2(a), Figure 2(b)) which is 


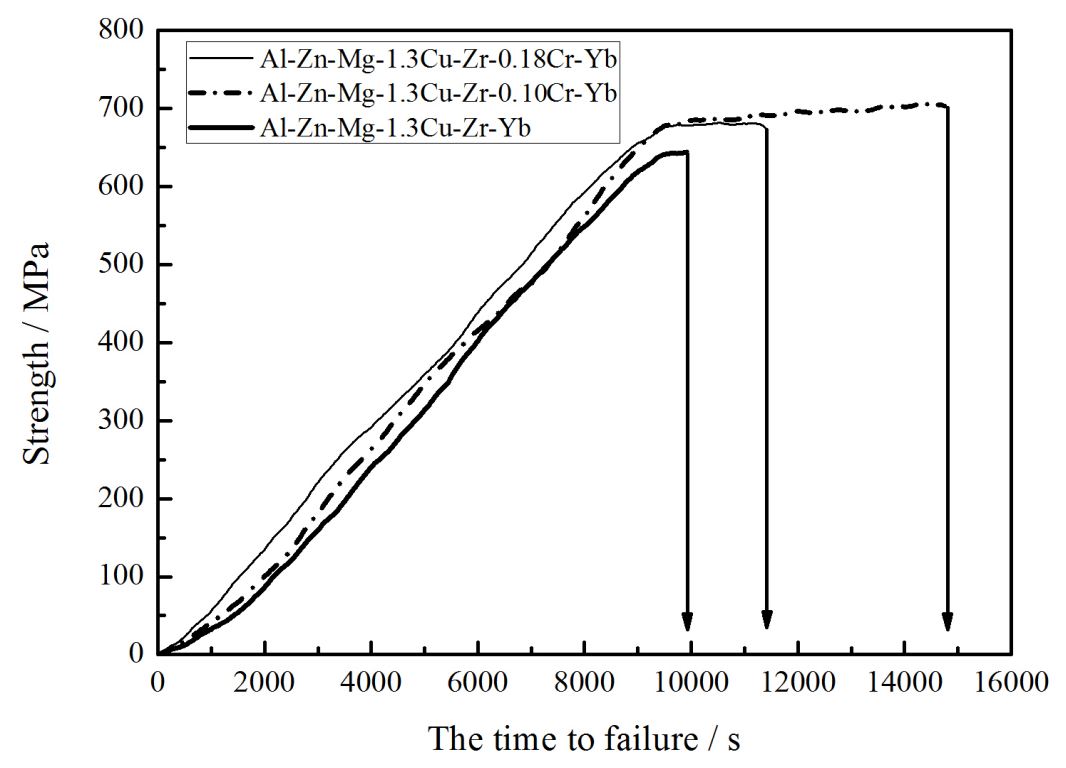

Figure 6. Different Cr content alloys slow stretch curve.

co lattice with the matrix. After high temperature treatment, most of the $\mathrm{Al}_{3}(\mathrm{Zr}$, $\mathrm{Yb})$ phase which is co lattice with the matrix changes to $\mathrm{Al}_{3}(\mathrm{Zr}, \mathrm{Yb})$ phase which is not co lattice, leading to the increase of recrystallization tendency. The addition of trace $\mathrm{Cr}$ results in the formation of $(\mathrm{Al}, \mathrm{Cr})_{3}(\mathrm{Zr}, \mathrm{Yb})$ phase with a small amount of $\mathrm{Cr}$ whose particle size is $10-20 \mathrm{~nm}$, which increases the stability of $\mathrm{Al}_{3}(\mathrm{Zr}, \mathrm{Yb})$ phase and improves the recrystallization resistance of the alloy. When $\mathrm{Cr}$ content is $0.18 \mathrm{wt} \%$, except for $\mathrm{L}_{12}$ type dispersion phase, there is also a coarse phase $\mathrm{Al}_{18} \mathrm{Mg}_{3} \mathrm{Cr}_{2}$ with the size of $50-150 \mathrm{~nm}$ in the alloy matrix, which will not be dissolved after solution heat treatment. As a heterogeneous phase, this phase can inhibit the formation of recrystallization to some extent, but its coarse size and coherent relationship with the matrix are not obvious, which can inhibit the recrystallization nucleation and growth process. The effect ratio (Al, $\mathrm{Zr})_{3}(\mathrm{Zr}, \mathrm{Yb})$ is different.

When $\mathrm{Cr}$ content is $0.1 \mathrm{wt} \%$, the fine dispersion can play a strong role in pinning relative to dislocation and sub grain boundary, hindering the transformation from sub grain boundary to large angle grain boundary, and greatly improving the stability of deformation recovery structure (Figure $1(b)$ ). The energy difference between small angle grain boundary and in crystal is much smaller than that between large angle grain boundary and in crystal, which hinders the enrichment of precipitated phase particles in grain boundary and reduces the recrystallization tendency of alloy. Moreover, the dispersion distribution of the precipitates in the crystal makes the dislocations only bypass the coherent dispersion phase, thus inhibiting the coplanar slip of dislocations and improving the deformation uniformity of the alloy. This is helpful to restrain the grain boundary fracture tendency and improve the stress corrosion resistance of the alloy.

As $\mathrm{Cr}$ containing dispersion phase can significantly inhibit matrix recrystalli- 
zation (Figures 1(a)-(c)), maintain deformation recovery structure and small angle grain boundary, it can significantly improve the fracture toughness of the alloy. Due to the low energy of small angle grain boundary, the possibility of aging precipitates enriching on it is very low. In addition, a large number of $\mathrm{Cr}$ containing dispersed phases are evenly distributed in the crystal, which makes grain growth difficult, promotes even deformation of the alloy, reduces the coplanar slip trend, avoids the grain boundary stress concentration caused by dislocation plugging at the grain boundary, thus reduces the tendency of grain boundary cracking caused by local stress concentration, and greatly improves the fracture toughness of the alloy.

\section{Conclusions}

1) With the increase of $\mathrm{Cr}$ content, the recrystallization and grain growth are inhibited, the strength, toughness and corrosion resistance of the alloy increase first and then decrease. When the Cr content is $0.1 \mathrm{wt} \%$, the performance of the alloy is the best.

2) The main reason is that $(\mathrm{Al}, \mathrm{Cr})_{3}(\mathrm{Zr}, \mathrm{Yb})$ phase containing trace $\mathrm{Cr}$ is formed when $\mathrm{Cr}$ content is $0.1 \mathrm{wt} \%$; when $\mathrm{Cr}$ content is increased to $0.18 \mathrm{wt} \%$, $\mathrm{Al}_{18} \mathrm{Mg}_{3} \mathrm{Cr}_{2}$ and $(\mathrm{Al}, \mathrm{Cr})_{3}(\mathrm{Zr}, \mathrm{Yb})$ phases are formed.

\section{Acknowledgements}

This work was supported by the National Key Research and Development Program of China (No. 2016YFB0300801) Major Research Equipment Development Projects of National Natural Science Foundation of China (No. 51327902) Ph. D. student self-exploration (2014zzts024).

\section{Conflicts of Interest}

The authors declare no conflicts of interest regarding the publication of this paper.

\section{References}

[1] Cao, C.X. (2008) One Generation of Material Technology, One Generation of Large Aircraft. Acta Aeronautica et Astronautica Sinica, 5, 701-706.

[2] Fang, H.C. and Chen, K.H. (2009) Current Research Status and Prospects of Ultra Strength Al-Zn-Mg-Cu Aluminum Alloy. Materials Science and Engineering of Powder Metallurgy, 14, 351-358.

[3] Antipov, V.V. and Senatorova, O.G. (2012) High-Strength Al-Zn-Mg-Cu Alloys and Light Al-Li Alloys. Metal Science and Heat Treatment, 53, 428-433. https://doi.org/10.1007/s11041-012-9410-x

[4] Zeng, Y., Yin, Z.-M., Zheng, Z.-Q. and Liu, Z.I. (2002) Present Research and Developing of Ultra Strength Aluminum Alloys. Journal of Central South University of Technology: Science and Technology, 33, 592-596.

[5] Lim, S.T., Yun, S.J. and Nam, S.W. (2004) Improved Quench Sensitivity in Modified Aluminum Alloy 7175 for Thick Forging Applications. Materials Science and Engi- 
neering $A$, 371, 82-90. https://doi.org/10.1016/S0921-5093(03)00653-1

[6] Mcnaughtan, D., Worsford, M. and Robinson, M.J. (2003) Corrosion Product Force Measurements in the Study of Exfoliation and Stress Corrosion Cracking in High Strength Aluminum Alloys. Corrosion Science, 45, 2377-2389.

https://doi.org/10.1016/S0010-938X(03)00050-7

[7] Li, J.-F., Jia, Z.-Q., Li, C.-X., et al. (2009) 7150 Study on Erosion Behavior of Aluminum Alloys and Corrosion Mechanism. Corrosion Science and Protection Technology, 21, 107-109.

[8] Xie, Y.H., Yang, S.J. and Dai, S.L. (2002) Application of Element Zr in Aluminum Alloys. Journal of Aeronautical Materials, 22, 52-61.

[9] Liu, S.D., Zhang, X.M., You, J.H., Zhang, X.Y. and Zhang, C. (2007) Effect of Quench Rates on Fracture Behavior of $\mathrm{AlZnMgCu}(\mathrm{Zr})$ Alloy. Transactions of Materials and Heat Treatment, 28, 45-49.

[10] Robson, J.D. and Prangnell, P.B. (2001) Dispersoid Precipitation and Process Modeling in Zirconium Containing Commercial Aluminium Alloys. Acta Materialia, 49, 599-613. https://doi.org/10.1016/S1359-6454(00)00351-7

[11] Royset, J. and Ryum, N. (2005) Scandium in Aluminium Alloys. International Material Reviews, 50, 19-44. https://doi.org/10.1179/174328005X14311

[12] Jones, M.J. and Humphreys, F.J. (2003) Interaction of Recrystallization and Precipitation: The Effect of $\mathrm{Al}_{3} \mathrm{Sc}$ on the Recrystallization Behaviour of Deformed Aluminium. Acta Materialia, 51, 2149-2159. https://doi.org/10.1016/S1359-6454(03)00002-8

[13] He, Y.D., Zhang, X.M. and You, J.H. (2007) Effects of Minor Contents of Sc and Zr on Microstructure and Mechanical Properties of Al-Zn-Mg-Cu Alloy. Rare Metal Materials and Engineering, 36, 665-670.

[14] Van, D.M.E., Dunand, D.C. and Seidman, D.N. (2005) Effects of Ti Additions on the Nanostructure and Creep Properties of Precipitation-Strengthened Al-Sc Alloys. Acta Materialia, 53, 4225-4235. https://doi.org/10.1016/j.actamat.2005.05.022

[15] Harada, Y. and Dunand, D.C. (2000) Creep Properties of $\mathrm{Al}_{3} \mathrm{Sc}$ and $\mathrm{Al}_{3}(\mathrm{Sc}, \mathrm{X})$ Intermetallics. Acta Materialia, 48, 3477-3487.

https://doi.org/10.1016/S1359-6454(00)00142-7

[16] Yin, M.L. (2015) Effect of SC on the Structure and Properties of Al-6Zn-2Mg-2.5Cu Alloy. Jilin University, Changchun.

[17] Tolley, A., Radmilovic, V. and Dahmen, U. (2005) Segregation in $\mathrm{Al}_{3}(\mathrm{Sc}, \mathrm{Zr})$ Precipitates in Al-Sc-Zr Alloys. Scripta Materialia, 52, 621-625. https://doi.org/10.1016/j.scriptamat.2004.11.021

[18] Dai, X.Y., Xia, C.Q. and Liu, C.B. (2006) The Effect of Sc for the Structure Properties of Al-Zn-Mg-Cu-Zr Alloy. Rare Metal Materials and Engineering, 35, 913-916.

[19] Fang, H.C. (2010) The Formation and Function of Dispersed Phase in Al-(Zn-Mg-Cu)-Zr-Cr-Re Alloy. Centre South University, Changsha.

[20] Fang, H.C., Shang, P.J., Huang, L.P., et al. (2012) Precipitates and Precipitation Behavior in Al-Zr-Yb-Cr Alloys. Materials Letters, 75, 192-195. https://doi.org/10.1016/j.matlet.2012.02.013

[21] Nes, E. and Wert, J.A. (1984) Modeling of Recrystallization in Alloys with a Bimodal Particle Size Distribution. Scripta Metallurgica, 18, 1433-1438. https://doi.org/10.1016/0036-9748(84)90381-8

[22] Nes, E., Ryum, N. and Hunderi, O. (1985) On the Zener Drag. Acta Metallurgica, 33, 11-22. https://doi.org/10.1016/0001-6160(85)90214-7 
[23] Ashby, M.F., Harper, J. and Lewis, J. (1969) The Inhibition of Grain-Boundary Motion by a Dispersion of Particles. Transactions of the Metallurgical Society of AIME, $245,413$. 